\title{
Easy and Rapid Purification of Highly Active Nisin
}

\author{
André Abts, ${ }^{1}$ Antonino Mavaro, ${ }^{1}$ Jan Stindt, ${ }^{1}$ Patrick J. Bakkes, ${ }^{1}$ Sabine Metzger, ${ }^{2}$ \\ Arnold J. M. Driessen, ${ }^{3}$ Sander H. J. Smits, ${ }^{1}$ and Lutz Schmitt ${ }^{1}$ \\ ${ }^{1}$ Institute of Biochemistry, Heinrich Heine University Düsseldorf, Universitätsstrabe 1, 40225 Düsseldorf, Germany \\ ${ }^{2}$ Biological and Medical Research Center, Heinrich Heine University Düsseldorf, Universitätsstrabe 1, 40225 Düsseldorf, Germany \\ ${ }^{3}$ Department of Molecular Microbiology, Groningen Biomolecular Sciences and Biotechnology Institute, \\ Zernike Institute for Advanced Materials and the Kluyver Centre for the Genomics of Industrial Microorganisms, \\ University of Groningen, Nijenborgh 7, 9747 AG Groningen, The Netherlands
}

Correspondence should be addressed to Lutz Schmitt, lutz.schmitt@hhu.de

Received 8 February 2011; Accepted 20 June 2011

Academic Editor: Piero Andrea Temussi

Copyright (C 2011 André Abts et al. This is an open access article distributed under the Creative Commons Attribution License, which permits unrestricted use, distribution, and reproduction in any medium, provided the original work is properly cited.

\begin{abstract}
Nisin is an antimicrobial peptide produced and secreted by several L. lactis strains and is specifically active against Gram-positive bacteria. In previous studies, nisin was purified via cation exchange chromatography at low $\mathrm{pH}$ employing a single-step elution using $1 \mathrm{M} \mathrm{NaCl}$. Here, we describe an optimized purification protocol using a five-step $\mathrm{NaCl}$ elution to remove contaminants. The obtained nisin is devoid of impurities and shows high bactericidal activity against the nisin-sensitive L. lactis strain NZ9000. Purified nisin exhibits an $\mathrm{IC}_{50}$ of $\sim 3 \mathrm{nM}$, which is a tenfold improvement as compared to nisin obtained via the one-step elution procedure.
\end{abstract}

\section{Introduction}

The capacity to produce antimicrobial peptides (AMPs) is widespread among Gram-positive bacteria. These AMPs are directed against competitive microorganisms in order to generate a selective advantage for the producer organism [1]. AMPs can be divided in three major classes. Class I consists of the so-called lantibiotics, which are posttranslationally modified peptides containing (methyl-)lanthionines, and have a typical size of $<5 \mathrm{kDa}$. Class II comprises heat-stable, nonmodified peptides of 37-58 amino acids (typical size of $<10 \mathrm{kDa}$ ) with the leader peptide, as for Class I AMPs, being removed during maturation. Class III contains AMPs that are heat labile and that are generally larger in size (roughly $30 \mathrm{kDa}$ ). Especially heat-stable peptides secreted by lactic acid bacteria have been studied extensively because of their potential use as natural preservatives in the food industry.

One of the best characterized AMPs is nisin, which is secreted by Lactococcus lactis and is a member of the Class I AMPs (for comprehensive reviews, see $[2,3]$ ). Although nisin has been used as a food preservative for more than fifty years, no significant bacterial resistance against nisin has been reported [4]. Nisin, encoded by the nis A gene, is a (methyl-)lanthionine ring containing peptide that is ribosomally synthesized as a prepeptide consisting of 57 amino acids. The NisA prepeptide is modified posttranslationally by the dehydratase NisB, which selectively dehydrates Serine and Threonine residues, and by the cyclase $\mathrm{NisC}$, which catalyzes lanthionine ring formation. NisT finally transports the modified prenisin across the cell membrane, and mature, biologically active nisin is produced upon cleavage of the leader peptide by the extracellular, membrane-anchored protease NisP. Mature nisin harbors three dehydrated amino acids (one dehydrobutyrine and two dehydroalanines), one lanthionine ring, and four methyl-lanthionine rings. In particular, these intramolecular rings are important for the biological activity of nisin [5]. It is worth mentioning that nisin induces its own synthesis via interaction with the twocomponent regulatory system NisRK.

Nisin is active against Gram-positive bacteria and exerts two killing mechanisms. Firstly, nisin inhibits cell-wall synthesis by binding to lipid II, an essential membrane-anchored cell-wall precursor, and secondly, nisin permeabilizes the target membrane. The binding of nisin to lipid II induces membrane integration of nisin resulting in the formation of a pore, likely composed of eight nisin and four lipid II 
molecules [6]. This highly specific interaction with lipid II is reflected by the low nano- to micromolar concentrations of nisin, sufficient to permeabilize the membrane of the target cells [7].

The bactericidal activity of AMPs is generally measured by quantifying growth inhibition of an AMP-sensitive target organism, grown either on agar plates or in liquid culture. On agar plates, zones of growth inhibition of the indicator organism can be easily visualized, and these so-called halo assays allow determination of the minimum inhibitory concentration (MIC) of the tested AMP [8]. Alternatively, bacterial growth can be monitored in liquid culture in dependence of the AMP concentration, by measuring the optical density. This method allows the simple determination of both the MIC and the $\mathrm{IC}_{50}$, that is, the concentration of AMP that inhibits cell growth by $50 \%$ [9].

Nisin from L. lactis, like almost all naturally produced AMPs, can be purified directly from the culture medium $[10,11]$. It is a cationic peptide, and therefore, commonly purified using cation exchange chromatography (cIEX) at acidic $\mathrm{pH}$, using high salt concentration for elution, typically a single-step elution with $1 \mathrm{M} \mathrm{NaCl}$ [12-16]. By using nisin purified via such a method, the $\mathrm{IC}_{50}$ and $\mathrm{MIC}$ values were determined for a variety of bacteria, such as various $L$. lactis strains, Enterococcus faecium, Bacillus anthracis, Bacillus subtilis, Staphylococcus aureus, and Streptococcus mutans [9, 17]. Whereas E. faecium and $S$. mutans were equally sensitive to nisin exhibiting an $\mathrm{IC}_{50}$ of $5 \mu \mathrm{M}$ and MIC of $12.5 \mu \mathrm{M}, L$. lactis $\mathrm{HP}$ was much more sensitive to nisin, with an $\mathrm{IC}_{50}$ of $14 \mathrm{nM}$ and MIC of $32 \mathrm{nM}$ [9]. Nisin shows promising activity towards clinical isolates of the Methicillin-resistant Staphylococcus aureus (MRSA) bacterium, Streptococcus pyogenenes, and several of the most severe human pathogens, including the multiresistant Streptococcus pneumoniae and vancomycin-resistant E. faecium or E. faecalis, against which new effective antibiotics are most urgently needed [1820]. In all these, studies purified nisin was used and the bactericidal activity of nisin was measured by determining the MIC or $\mathrm{IC}_{50}$.

Here, we describe a rapid and easy nisin purification protocol, optimized to yield active, monomeric nisin. For this purpose, nisin was either produced from L. lactis strain NZ9700 or purchased in the form of a lyophilized powder that contains $2.5 \%(\mathrm{w} / \mathrm{w})$ nisin. Nisin from both sources was purified and tested for bactericidal activity using the nisinsensitive L. lactis NZ9000 strain. During the purification low molecular weight contaminants are removed, which results in purified nisin with high specific activity. This allows a more accurate and reproducible determination of the biological activity of nisin.

\section{Material and Methods}

\subsection{Production and Purification of Nisin}

2.1.1. Nisin Produced by L. Lactis. A culture of the L. lactis strain NZ9700 was grown overnight in M17 medium containing $0.5 \%(\mathrm{w} / \mathrm{v})$ glucose (GM17) at $30^{\circ} \mathrm{C}$. Next, $100 \mathrm{~mL}$ of the overnight culture was used to inoculate 21 of GM17, and cells were grown at $30^{\circ} \mathrm{C}$. At an $\mathrm{OD}_{600}$ of 0.8 , the culture was supplemented with nisin (Sigma) to a final concentration of $1 \mathrm{ng} / \mathrm{ml}$ cell culture to ensure nisin production and growth was continued over night. Next, cells were removed by centrifugation ( $30 \mathrm{~min}$., 6000xg at $4^{\circ} \mathrm{C}$ ). The supernatant was used and diluted with 11 of $50 \mathrm{mM}$ lactic acid pH 3 resulting in a 31 solution with a $\mathrm{pH}$ of 5 . This solution was loaded on a $5 \mathrm{~mL}$ HiTrap SP HP cation exchange (cIEX) column (GE Healthcare) using a flow rate of $4 \mathrm{~mL} / \mathrm{min}$. Due to the large volume, this step is optimally performed overnight. Protein elution was monitored by measuring the absorbance at $215 \mathrm{~nm}$. Unfortunately, it is not possible to detect nisin at $280 \mathrm{~nm}$, because it does not contain any aromatic amino acids; therefore, the $215 \mathrm{~nm}$ was chosen as wavelength. The column was subsequently washed with $50 \mathrm{mM}$ lactic acid $\mathrm{pH} 3$ until a stable baseline was reached to remove nonspecifically bound material. Peptides were eluted by increasing the $\mathrm{NaCl}$ concentration stepwise using a flow rate of $1 \mathrm{~mL} / \mathrm{min}$, resulting in elution fractions with $200 \mathrm{mM}$ (Step I), $400 \mathrm{mM}$ (Step II), $600 \mathrm{mM}$ (Step III), $800 \mathrm{mM}$ (Step IV) and $1 \mathrm{M}$ (Step V) $\mathrm{NaCl}$. To remove $\mathrm{NaCl}$, protein in the elution fractions was precipitated with $20 \%$ (v/v) trichloroacetic acid (TCA) overnight at $4^{\circ} \mathrm{C}$. Precipitated protein was washed two times with ice-cold acetone to remove residual TCA. Finally, the protein pellet was suspended in $50 \mathrm{mM}$ lactic acid $\mathrm{pH}$ 3. Nisin concentrations were determined by a colorimetric assay (Pierce BCA Protein Assay Kit, Thermo scientific) by measuring the absorbance at $584 \mathrm{~nm}$ according to the protocol of the manufacturer.

2.1.2. Purchased Nisin. Commercial nisin (Sigma) is available as a lyophilized powder containing $\sim 2.5 \%(\mathrm{w} / \mathrm{w})$ nisin. $1.3 \mathrm{~g}$ of nisin powder (corresponding to $32.5 \mathrm{mg}$ nisin) was dissolved in $100 \mathrm{~mL} 50 \mathrm{mM}$ lactic acid pH 3 and filtered through a $0.45 \mu \mathrm{m}$ membrane filter (Pall Corporation). The nisin solution was applied to a $5 \mathrm{~mL}$ HiTrap SP HP cation exchange column (GE Healthcare) at a flow rate of $2 \mathrm{~mL} / \mathrm{min}$, whereas elution was performed at a flow rate of $1 \mathrm{~mL} / \mathrm{min}$. Nisin purification, precipitation, and concentration determination were carried out as described above.

2.2. Tricine-SDS-PAGE. Tricine-SDS-PAGE was essentially carried out as described in [21]. For analysis, $16 \mu \mathrm{L}$ sample was supplemented with $4 \mu \mathrm{L} 5 \mathrm{x}$ SDS sample buffer $(0.2 \mathrm{M}$ Tris-HCl, pH 6.8, 10\% (w/v) SDS, 40\% (v/v) glycerol, $0.02 \%$ $(\mathrm{w} / \mathrm{v})$ bromophenol blue, and $10 \mathrm{mM}$ DTT) and loaded on a tricine gel consisting of a stacking gel containing 5\% acrylamide and a separation gel containing 16\% acrylamide. The gel was run at $100 \mathrm{~V}$ for 2 hours, and proteins were detected via silver staining. For all purification fractions, $3.2 \mu \mathrm{g}$ of total protein was analyzed.

2.3. MALDI-TOF Mass Spectrometry. Samples obtained from cIEX chromatography were precipitated with TCA and washed with acetone as described above. The protein pellets 
were then dried for $15 \mathrm{~min}$. at $30^{\circ} \mathrm{C}$ in a vacuum concentrator (Eppendorf concentrator plus). Dried pellets were stored at $-20^{\circ} \mathrm{C}$ until analysis. For mass spectrometric analysis, the samples were dissolved in water with $1 \%(\mathrm{v} / \mathrm{v})$ formic acid. Measurements were performed using a MALDI-TOF instrument (Voyager-DE STR, Applied Biosystems) with a nitrogen laser $(\lambda=337 \mathrm{~nm})$ operating in reflector mode with $25 \mathrm{kV}$ acceleration voltage. The samples were prepared by the standard dried-droplet procedure, by applying $0.5 \mu \mathrm{L}$ of 2,5-dihydroxybenzoic acid (DHB) matrix solution (10 mg in $1 \mathrm{~mL}$ water) plus $0.5 \mu \mathrm{L}$ of sample solution. The droplet was dried by a gentle flow of air. An external calibration with the monomer ion of des-Pro-Bradykinin, Sub P, Bombesin, and Melittin was used. The spectrum was obtained by averaging 200 laser shots.

2.4. $I C_{50}$ Determination of Nisin. To investigate the antimicrobial activity of nisin, the nisin sensitive $L$. lactis strain NZ9000 [22] was grown in a 96-well plate in GM17 medium. The total volume in each well was $200 \mu \mathrm{L}$, consisting of $50 \mu \mathrm{L}$ sample and $150 \mu \mathrm{L}$ GM17 containing L. lactis NZ9000 cells (starting $\mathrm{OD}_{600}=0.1$ ). Samples were prepared by diluting nisin obtained from various cIEX elution fractions in $50 \mathrm{mM}$ lactic acid $\mathrm{pH} 3$ to yield final protein concentrations ranging from $0.15 \mathrm{nM}$ to $300 \mathrm{nM}$ in the wells. $50 \mathrm{mM}$ lactic acid $\mathrm{pH}$ 3 without protein served as positive growth control. Cells were grown at $30^{\circ} \mathrm{C}$, and the optical density was monitored at $620 \mathrm{~nm}$ every $20 \mathrm{~min}$ for a period of 8 hours (96 plate reader $\mathrm{BMG})$. To determine the $\mathrm{IC}_{50}$ values, the optical density was normalized and plotted against the log of the nisin concentration. Data were evaluated according to

$$
Y=\frac{\text { OD } \min +(\text { OD } \max -\text { OD } \min )}{1+10^{((\log (\mathrm{IC} 50)-X) * \text { slope })}} .
$$

The $\mathrm{OD}_{\max }$ value describes the normalized $\mathrm{OD}_{600}$ value in the starting plateau. The $\mathrm{OD}_{\min }$ value corresponds to the normalized $\mathrm{OD}_{600}$ of the end plateau value. $Y$ stands for the normalized optical density value, and $X$ represents the logarithmic concentration of the peptide. The $\mathrm{IC}_{50}$ value is calculated as the value of the peptide concentration used where the growth inhibition (or $\mathrm{OD}_{600}$ ) is $50 \%$. This corresponds to the inflection point of the resulting curves.

2.5. Growth Inhibition Visualized by a Halo Assay. The antimicrobial activity of the different nisin preparations was assessed by means of a halo assay. Purified nisin obtained from the different cIEX elution fractions were supplemented $(16 \mu \mathrm{L})$ with $4 \mu \mathrm{L}$ of $5 \mathrm{x}$ SDS sample buffer and tricine-SDS-PAGE was carried out as described above. After electrophoresis the gel was incubated for $30 \mathrm{~min}$ in an aqueous solution containing $20 \%(\mathrm{v} / \mathrm{v})$ isopropanol and $10 \%(\mathrm{v} / \mathrm{v})$ acetic acid. Subsequently, the gel was washed two times for $30 \mathrm{~min}$ in $\mathrm{ddH}_{2} \mathrm{O}$. At this stage, the gel was kept in $\mathrm{dd}_{2} \mathrm{O}$ at $8^{\circ} \mathrm{C}$ until usage. Finally, the gel was overlaid with GM17-agar ( $0.5 \%$ w/v agar) containing L. lactis NZ9000 cells at an $\mathrm{OD}_{600}$ of 0.1 . After solidification, the overlaid gel was incubated overnight at $30^{\circ} \mathrm{C}$ to allow for bacterial growth. The bactericidal activity of nisin is readily visualized by the presence of clear zones (halos) resulting from growth inhibition.

\section{Results}

\subsection{Purification of Nisin}

3.1.1. Lyophilized Commercial Nisin. To determine the antimicrobial activity of commercially available nisin, we used a lyophilized powder, which contains $\sim 2.5 \%(\mathrm{w} / \mathrm{w})$ nisin. To further purify nisin, we initially performed SP Sepharose cation exchange chromatography using $1 \mathrm{M} \mathrm{NaCl}$ to elute the bound nisin. Subsequent SDS-PAGE analysis of the eluate revealed a major protein band corresponding to a peptide with a molecular mass of about $3.5 \mathrm{kDa}$ (data not shown) in line with the calculated mass of $3354 \mathrm{Da}$ for mature nisin. However, several higher molecular weight components were also present. It is of note that these contaminants are not readily visualized by Coomassie Brilliant Blue staining, whereas these impurities are clearly detected by silver staining. Nisin purified via this method showed antimicrobial activity against $L$. lactis NZ9000 exhibiting an $\mathrm{IC}_{50}$ of $30 \pm 12 \mathrm{nM}$.

The presence of contaminants prompted us to optimize the purification of nisin. We first tested elution with a linear gradient (50 times the column volume) ranging from 0-1 M NaCl. This approach, however, resulted in a broad peak eluting throughout the $\mathrm{NaCl}$ gradient and further analysis revealed no improvement when compared to the single-step $1 \mathrm{M} \mathrm{NaCl}$ elution (data not shown). In contrast, a substantial improvement was achieved when a five-step $\mathrm{NaCl}$ step gradient was used to elute nisin from the cIEX column (Figure 1(a)). Bound protein eluted at every step as evidenced by the elution profile and subsequent tricineSDS-PAGE analysis (Figure 2(a)). The Step II elution fraction contained the bulk of nisin as evident by the major protein band with a corresponding molecular mass of $\sim 3.5 \mathrm{kDa}$, whereas substantially lower amounts of nisin were detected in elution fractions I, III, and IV. In the Step V fraction no nisin was visible. The Step I and II elution fractions contained exclusively nisin, while elution fractions III-V contained predominantly higher molecular weight compounds (ranging from $6 \mathrm{kDa}-70 \mathrm{kDa}$ ). In the latter fractions compounds with molecular weights of $\sim 8 \mathrm{kDa}$ and $\sim 10 \mathrm{kDa}$ were most prominent. The total protein concentration of the elution fractions was determined to be: $2.1 \mathrm{mg} / \mathrm{mL}$ for Step I $(200 \mathrm{mM} \mathrm{NaCl}), 7.5 \mathrm{mg} / \mathrm{mL}$ for Step II $(400 \mathrm{mM} \mathrm{NaCl})$, $1.9 \mathrm{mg} / \mathrm{mL}$ for Step III $(600 \mathrm{mM} \mathrm{NaCl}), 0.5 \mathrm{mg} / \mathrm{mL}$ for Step IV $(800 \mathrm{mM} \mathrm{NaCl})$ and $0.4 \mathrm{mg} / \mathrm{mL}$ for Step V $(1 \mathrm{M} \mathrm{NaCl})$ (Table 1). In Step II, $~ 60 \%$ of the total purified nisin eluted. Thus, it appears that $400 \mathrm{mM} \mathrm{NaCl}$ is sufficient to elute the vast majority of the nisin molecules. More importantly, the nisin eluting under these conditions is essentially devoid of contaminants.

3.1.2. Nisin Produced by L. Lactis. An alternative to purchasing nisin is to produce it in the laboratory, since $L$. lactis strains that secrete nisin in large amounts are readily 


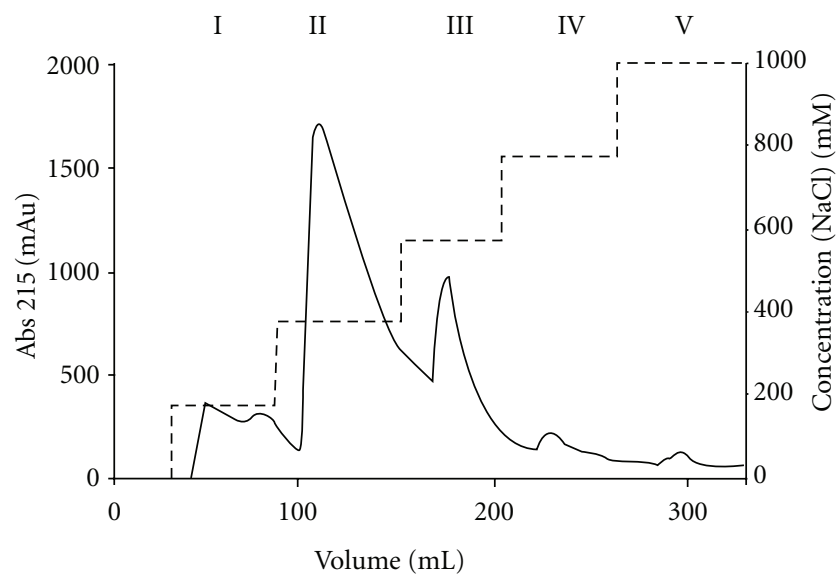

(a)

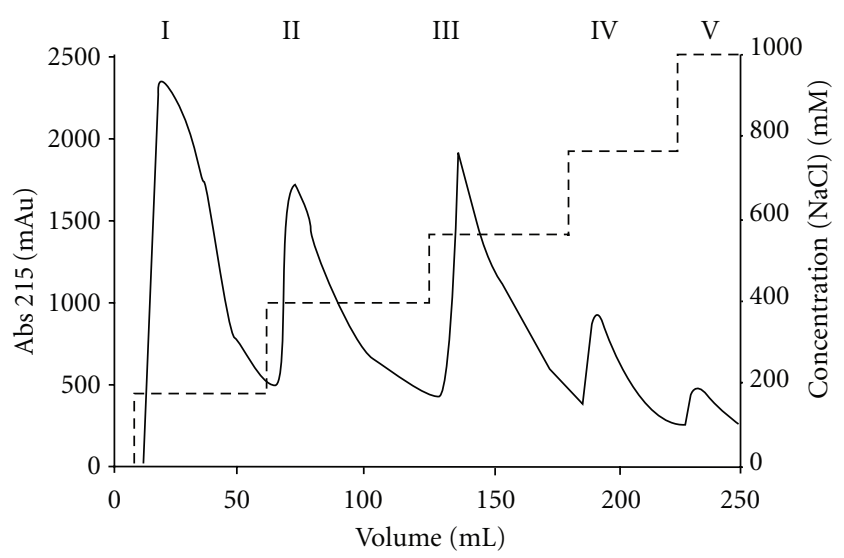

(b)

FIgURE 1: Purification of nisin via cation exchange chromatography. The elution profiles of the purification of commercial nisin (a) and nisin produced by L. lactis NZ9700 (b) are shown. In both cases, nisin is eluted from the column using a five-step gradient with $200 \mathrm{mM}$ (Step I), $400 \mathrm{mM}$ (Step II), $600 \mathrm{mM}$ (Step III), $800 \mathrm{mM}$ (Step IV) and $1 \mathrm{M} \mathrm{NaCl}$ (Step V). The different elution steps and corresponding $\mathrm{NaCl}$ concentrations are indicated by the dashed line and the right $y$-axis, respectively. Protein was detected by measuring the absorbance at $215 \mathrm{~nm}$.

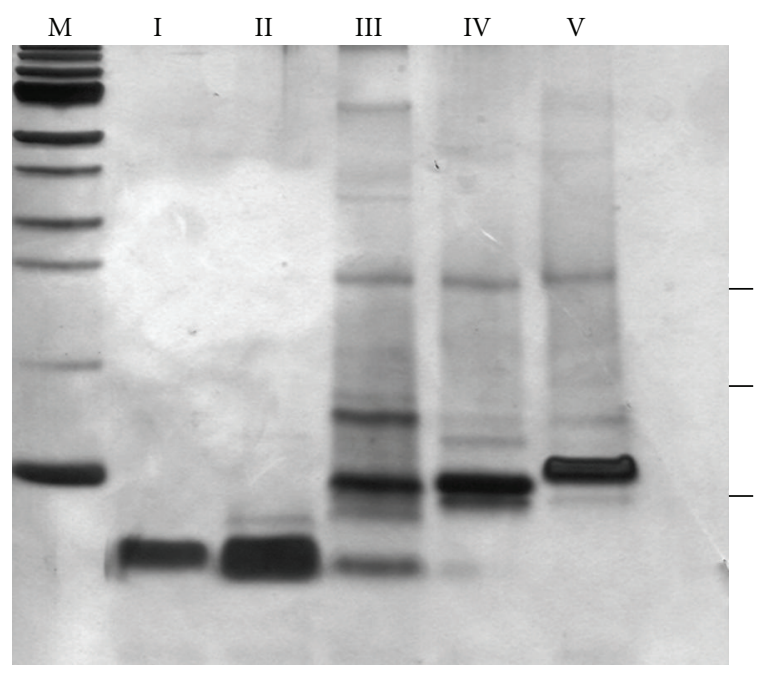

(a)

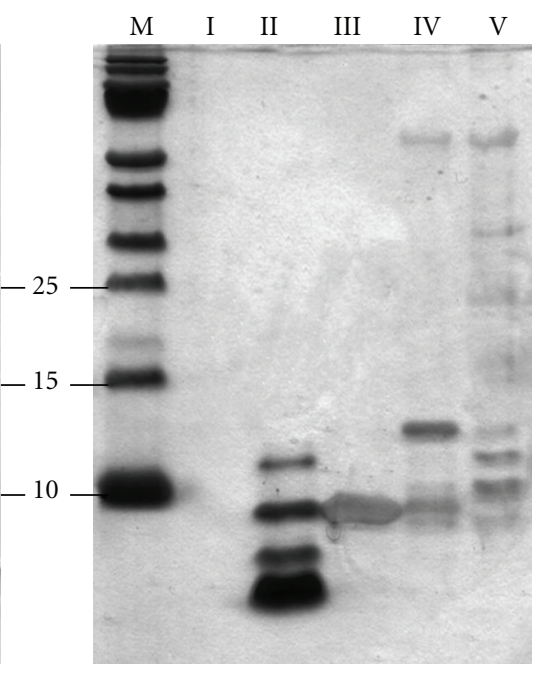

(b)

FIgure 2: Tricine-SDS-PAGE analysis of the cIEX purification of nisin. Purification of commercial nisin (a) and nisin secreted by the $L$. lactis NZ9700 strain (b). M, marker proteins; I, elution with $200 \mathrm{mM} \mathrm{NaCl}$; II, elution with $400 \mathrm{mM} \mathrm{NaCl}$; III, elution with $600 \mathrm{mM}$ NaCl; IV, elution with $800 \mathrm{mM} \mathrm{NaCl}$; V, elution with $1 \mathrm{M} \mathrm{NaCl}$. Protein was visualized by silver staining. The three lowest marker proteins are indicated with molecular weights $(\mathrm{kDa})$.

TABLE 1: $\mathrm{IC}_{50}$ values of each nisin containing fraction eluted from the cIEX column. Values are combined data from at least three independent nisin purifications and subsequent inhibition experiments.

\begin{tabular}{|c|c|c|c|c|}
\hline \multirow[b]{2}{*}{ Elution step } & \multicolumn{2}{|c|}{ Purchased nisin } & \multicolumn{2}{|c|}{ NZ9700 secreted nisin } \\
\hline & $\mathrm{IC}_{50}(\mathrm{nM})$ & Yield (mg) & $\mathrm{IC}_{50}(\mathrm{nM})$ & Yield (mg) \\
\hline Step I (200 mM) & $35.1 \pm 0.1$ & 4.2 & n.i. & 0.06 \\
\hline Step II (400 mM) & $2.6 \pm 0.1$ & 15.1 & $11.2 \pm 0.3$ & 5.90 \\
\hline Step III (600 mM) & $6.9 \pm 0.2$ & 3.8 & n.i. & 3.29 \\
\hline Step IV (800 mM) & $27.0 \pm 0.2$ & 1.1 & n.i. & 0.14 \\
\hline Step V (1 M) & n.i. & 0.8 & n.i. & 0.45 \\
\hline
\end{tabular}

n.i $=$ no inhibition observed under the experimental setup. 
available. We used L. lactis NZ9700 grown in GM17 medium to produce nisin (see Section 2). Culture supernatant containing nisin was subjected to cIEX chromatography using the same five-step $\mathrm{NaCl}$ elution gradient as described above. Here, a high absorbance at $215 \mathrm{~nm}$ occurred at the Step I elution (Figure 1(b)), but this did not correspond to nisin or other proteins as evidenced by silver-staining following SDS-PAGE analysis (Figure 2(b), lane 2). Likely, this high absorbance is due to ingredients from the growth medium, which contains large amounts of peptone, tryptone, and yeast extract. This was confirmed by a run with only GM17 media (data not shown). The remainder of the elution profile is similar to that of the lyophilized nisin purification, with two major absorbance peaks observed for the Step II and III fractions (Figure 1(b)). Analysis of the protein content of the different elution fractions revealed that nisin is exclusively found in the $400 \mathrm{mM} \mathrm{NaCl}$ elution fraction (Figure 2(b)). The total protein concentration of the $400 \mathrm{mM}$ elution fraction was $2.9 \mathrm{mg} / \mathrm{mL}$. However, whereas nisin is most prominent in this fraction, components with a $\mathrm{MW}$ $6 \mathrm{kDa}, \sim 10 \mathrm{kDa}$, and $\sim 12 \mathrm{kDa}$ are also present. The $0.6-1 \mathrm{M}$ elution fractions on the other hand contained compounds with molecular weights ranging from $8 \mathrm{kDa}-70 \mathrm{kDa}$, similar to those observed for the purification of lyophilized nisin (Figures 2(a) and 2(b)). When compared to the purification of lyophilized nisin, nisin purified from GM17 medium still contained contaminants. This difference in purity may relate to differences in the loaded material. The lyophilized nisin powder (also containing denatured milk solids) was dissolved in $50 \mathrm{mM}$ lactic acid, whereas nisin produced by $L$. lactis NZ9700 was applied to the cationic exchange column as a $1: 2$ mixture of GM17 culture medium and $50 \mathrm{mM}$ lactic acid, respectively.

We considered the possibility that the compounds with molecular weights of 6-8 kDa may represent the unprocessed form of nisin. Immature nisin, that is, nisin still containing the leader sequence, has a molecular weight of $5.9 \mathrm{kDa}$ and may arise if inefficient leader cleavage by the protease NisP occurs. We therefore performed Western-blot analysis using a polyclonal antibody raised against the nisin leader sequence. Purified prenisin secreted by a $L$. lactis strain lacking NisP was used as a positive control for Westernblot analysis [23]. For all elution fractions, no signals were observed suggesting that the observed compounds are not derived from prenisin (data not shown).

3.2. Biological Activity of Nisin. To test the biological activity of the purified nisin, we used L. lactis NZ9000 as indicator organism. L. lactis NZ9000 is a derivative of the plasmidcured L. lactis MG1363 and contains the nisRK genes inserted in the chromosomal pepN locus [24]. This strain is commonly used as the host for nisin-induced expression system (NICE) purposes [25]. However, since this strain lacks the nisin immunity genes nisIFEG, it is sensitive to nisin [22]. The antimicrobial activities associated with the different elution fractions obtained as described above were tested in a so-called halo assay. For this, the various fractions containing nisin were analyzed by tricine-SDS-PAGE and the tricine gel was overlaid with GM17-agar containing nisin sensitive bacteria (see Section 2). The biological activity of nisin is visualized by the growth inhibition zones (halos) at the position where nisin is present. The results for the lyophilized and the laboratory produced nisin are shown in Figures $3(\mathrm{a})$ and 3(b), respectively. After overnight incubation at $30^{\circ} \mathrm{C}$ halos were observed for elution Step I-IV for the lyophilized nisin, while for the produced nisin, a halo was only observed for elution fraction II. For both purifications, the highest level of growth inhibition was observed for fraction II. Importantly, the zones of inhibition are located only at the position of the $3.5 \mathrm{kDa}$ nisin peptide (Figure 3 ). Thus, purified nisin was biologically active and no growth inhibitory activity is associated with the higher molecular weight compounds.

3.3. Mass Spectrometry. To assess and confirm the presence of nisin in the individual cIEX elution fractions (Step II$\mathrm{V}$ ) of the lyophilized nisin purification, we applied MALDITOF mass spectrometry. The $400 \mathrm{mM} \mathrm{NaCl}$ elution fraction contained only one peptide with a molecular mass of $3355.09 \mathrm{Da}$ (Figure 4), which is in agreement with the calculated mass of $3354.07 \mathrm{Da}$ for nisin. Peak integration of the total mass spectrum revealed that the $400 \mathrm{mM}$ elution fraction contains $>98 \%$ of nisin, indicating that this fraction is essentially devoid of contaminants. Nisin was also found in the $600 \mathrm{mM}$ and $800 \mathrm{mM}$ elution fractions, whereas nisin was not detected in the $1 \mathrm{M} \mathrm{NaCl}$ fraction. These results are in agreement with tricine-SDS-PAGE analysis (Figure 2(a)).

However, the $0.6-1 \mathrm{M} \mathrm{NaCl}$ elution fraction contained several peptides with higher molecular masses. Subsequent tandem MS analysis of these peptides yielded in-sequence tags of eight amino acids and six amino acids, which unfortunately could not be assigned to specific proteins. This was due to the fact that the obtained sequence tags were too short and when blasted gave multiple different protein hits (data not shown). Nevertheless, the obtained sequence tags did not match with the primary sequence of (pre)nisin. Therefore, it can be excluded that the peptide contaminants with molecular masses of $\sim 6-8 \mathrm{kDa}$ are derived from prenisin.

3.4. Antimicrobial Activity of Purified Nisin. To quantitatively assess the growth inhibitory activity of nisin obtained from the different purification fractions, a liquid culture assay was performed using L. lactis NZ9000 as reporter organism. The optical density of the L. lactis NZ9000 cultures after 5 hours of growth was plotted against the total protein concentration of the nisin purification fractions. Results are shown for both, the lyophilized (Figure 5(a)) and the produced nisin (Figure 5(b)), respectively. The resulting growth curves and the calculated $\mathrm{IC}_{50}$ values are shown in Figure 5 and Table 1 , respectively.

For lyophilized nisin, all cIEX elution fractions exhibited growth inhibitory activity, however, with very distinct $\mathrm{IC}_{50}$ values (Figure 5(a) and Table 1). The Step II elution fraction displayed the highest bactericidal activity with an $\mathrm{IC}_{50}$ of $2.6 \pm 0.1 \mathrm{nM}$. The other elution fractions showed substantially higher $\mathrm{IC}_{50}$ values. Whereas the Step V elution 


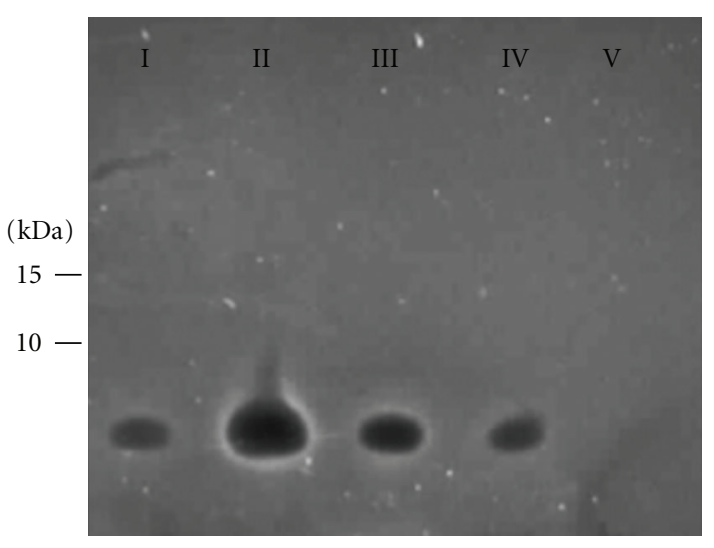

(a)

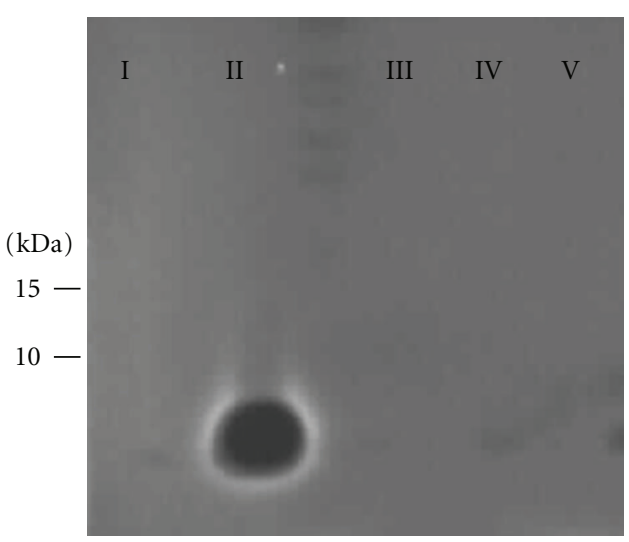

(b)

FIGURE 3: Bactericidal activity of the various nisin purification fractions. Equal amounts of protein of the different elution fractions (Step I-V) from the purification of commercial nisin (a) and from nisin secreted by the L. lactis NZ9700 strain (b) were run on a tricine-SDS-PA gel and overlaid with nisin-sensitive L. lactis NZ9000 cells (see Section 2). The position of marker proteins with known molecular weight $(\mathrm{kDa})$ are indicated on the left. The growth inhibition zones are visible as dark areas. Lanes I-V represent the five different elution fractions of the cation exchange chromatography. For both purifications, maximum growth inhibition is observed for the Step II elution fraction $(400 \mathrm{mM} \mathrm{NaCl})$. Notably, the growth inhibition zone is only visible at a position of $\sim 3.5 \mathrm{kDa}$.

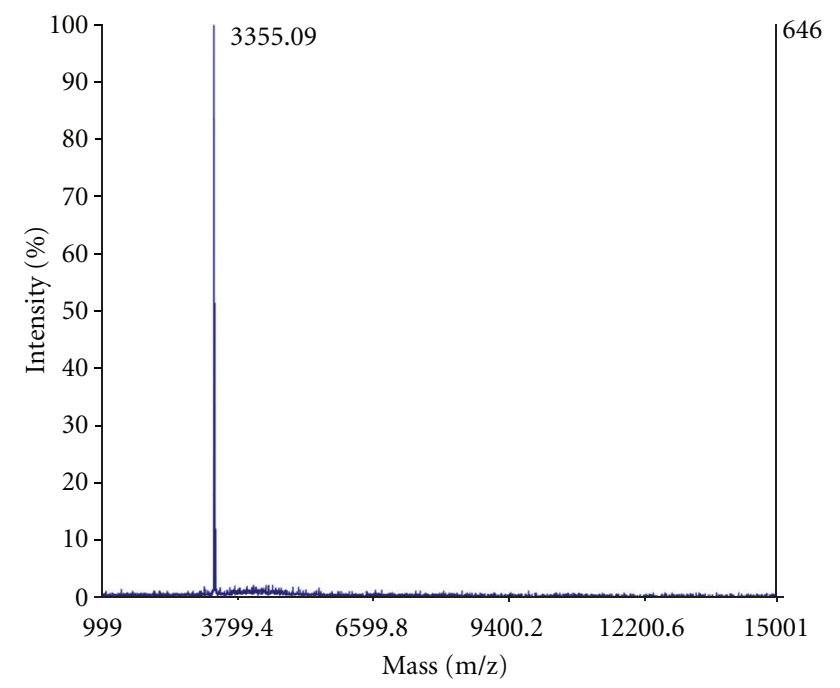

Figure 4: MALDI-TOF mass spectrometry analysis of purified nisin. Mass spectrum of the Step II elution fraction $(400 \mathrm{mM} \mathrm{NaCl})$ from the lyophilized nisin purification (for corresponding tricineSDS-PAGE analysis, see Figure 2(a), lane II).

fraction had only an inhibitory effect at the highest tested concentrations, the Step I, III, and IV elution fractions exhibited an $\mathrm{IC}_{50}$ value of $35.1 \pm 0.1 \mathrm{nM}, 6.9 \pm 0.2 \mathrm{nM}$, and $27.0 \pm 0.2 \mathrm{nM}$, respectively. Thus, the $400 \mathrm{mM} \mathrm{NaCl}$ elution fraction contains not only the bulk of nisin, it also contains nisin that displayed the highest specific activity.

A similar observation can be made for nisin purified from the medium (Figure 5(b)). However, here only the $400 \mathrm{mM}$ elution fraction shows bactericidal activity, which is in agreement with tricine-SDS-PAGE analysis (Figure 2(b)) and the halo assay (Figure $3(\mathrm{~b})$ ). The calculated $\mathrm{IC}_{50}$ of $11.2 \pm 0.3 \mathrm{nM}$ is, however, $\sim 4$-fold higher than that of the corresponding fraction obtained from the purification of lyophilized nisin. We attribute this difference to the contaminants that are still present (Figure 2(b), lane II). Nevertheless, for both purifications the highest bactericidal activity is associated with the fraction that contains the highest amount of nisin (Figures 2-3 and 5). Taken together the data indicate that nisin obtained from the Step II elution fraction has the highest specific activity.

To determine whether $\mathrm{NaCl}$ used for elution has an effect on nisin activity, we repeated the experiment and adjusted the concentration of $\mathrm{NaCl}$ after elution in every fraction to $500 \mathrm{mM}$ either by dilution with buffer without salt or by adding buffer and salt. Precipitated protein from these fractions was subsequently used for growth experiments as described above. In all cases, the $\mathrm{IC}_{50}$ values of the "salt experiment" were slightly higher than when measured directly after elution, indicating that more nisin is needed to inhibit cell growth by $50 \%$ (data not shown). This indicates that residual salt does not have a major influence on the activity of nisin. It can, therefore, be excluded that the differences in $\mathrm{IC}_{50}$ values of the various nisin containing elution fractions are induced by the amounts of $\mathrm{NaCl}$ used to elute nisin from the column.

\section{Discussion}

AMPs produced by Gram-positive bacteria form a unique group secreted peptides [1]. Their uniqueness of especially the lantibiotic group of AMPs, resides in the posttranslational modifications, such as dehydration of amino acids and intramolecular thioether bridges. One of the bestcharacterized AMP is nisin, a compound used for more than 40 years in up to 80 countries as an effective agent to combat food-borne pathogens. Nisin has been purified and its antimicrobial activity verified in numerous of studies [9]. 


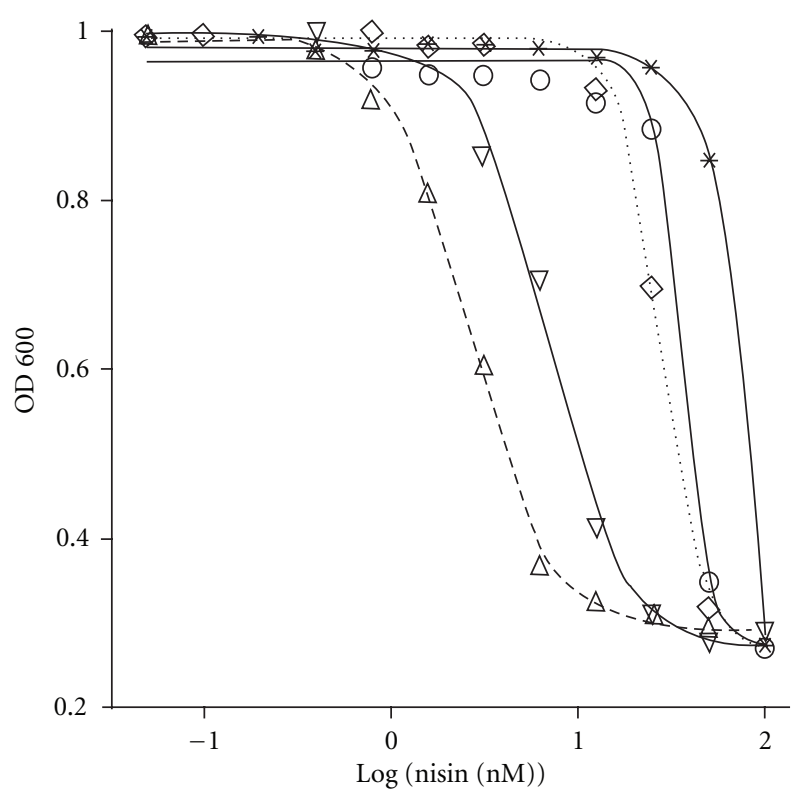

(a)

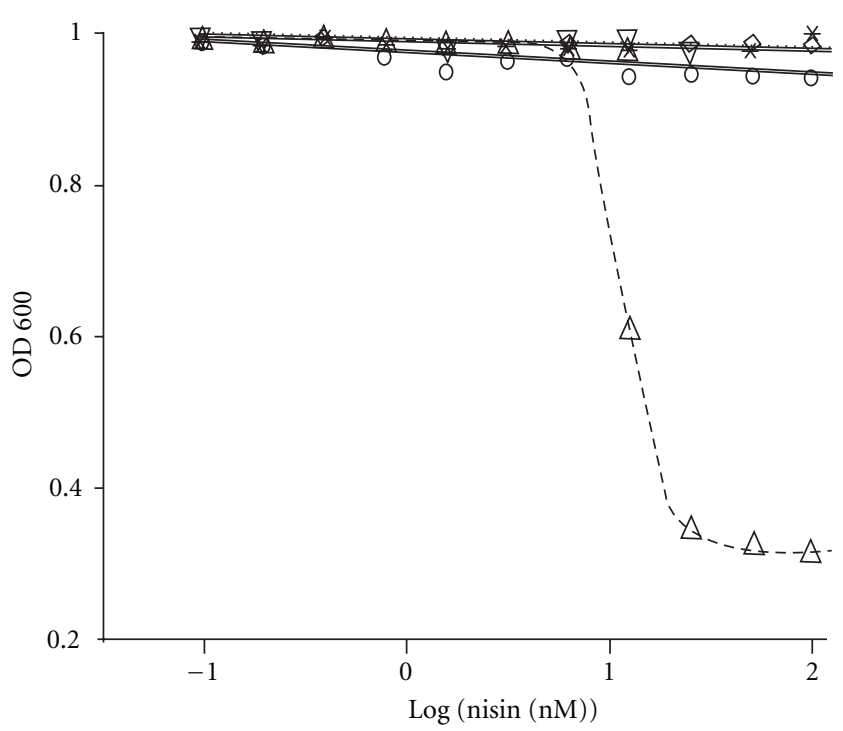

(b)

FIGURE 5: $\mathrm{IC}_{50}$ determination of the nisin purification fractions. Growth inhibition experiments were performed with nisin obtained from the different elution fractions of the purifications of commercial nisin (a) and of nisin secreted by the L. lactis NZ9700 strain (b). The log of the used nisin concentration of each elution fraction is plotted against the normalized optical density of L. lactis NZ9000 after five hours of growth. Shown are the inhibition curves for the $\mathrm{NaCl}$ elution fractions of $200 \mathrm{mM}(\mathrm{o}), 400 \mathrm{mM}(\triangle), 600 \mathrm{mM}(\nabla), 800 \mathrm{mM}(\diamond)$, and $1 \mathrm{M}$ $(*)$. Data was fitted and evaluated according to (1).

Commonly, nisin and other cationic AMPs are purified using a single $1 \mathrm{M} \mathrm{NaCl}$ elution step, from a cIEX column at an acidic $\mathrm{pH}[12-14,16,26]$.

The activity of AMPs is strictly dependent on the target organism. For example, the $\mathrm{IC}_{50}$ value of nisin ranges from $14 \mathrm{nM}$ for L. lactis $\mathrm{HP}$ to $5 \mu \mathrm{M}$ for Vancomycin-resistant $E$. faecium, with respective MICs of $32 \mathrm{nM}$ and $12.5 \mu \mathrm{M}$ [9]. In all these studies, it is noticeable that there is a large variation in the sensitivity to nisin between isogenic strains of Gram-positive bacteria, whereas some bacteria are inherently resistant to nisin. There are several mechanisms by which bacteria can become resistant to an antibiotic. The most prominent example is the enzymatic destruction or modification of the antibiotic, thereby rendering it ineffective. $\beta$-Lactamases, for example, degrade the $\beta$-lactam ring of penicillins. A second important mechanism of resistance is shielding of the target such that the antibiotic cannot get access to it-for example, by cell-surface alterations (capsules S-layers) or by active extrusion by efflux pumps. Moreover, the resistance of the AMP producer organism towards its secreted AMP (autoimmunity) is typically based on ATPbinding cassette $(\mathrm{ABC})$ transporters which expel the AMP from the membrane.

In L. lactis NZ9700, cells autoimmunity is mediated by the scavenger protein NisI and the ABC transporter NisFEG [5]. L. lactis cells lacking the NisIFEG defense system (e.g., L. lactis NZ9000) are sensitive to nisin and can be used as indicator organism to measure the biological activity of nisin. The nisI and nisFEG genes are part of the nis operon and are expressed in concert with the genes involved in nisin production and secretion. Recently, in nisin-non-producing L. lactis, nisin resistance was shown to be conferred by a specific nisin resistance gene $(n s r)$, which encodes a $35 \mathrm{kDa}$ nisin resistance protein (NSR). NSR proteolytically removes the last six amino acids of nisin, thereby reducing its bactericidal activity by a factor of 100 [27].

The level of intrinsic resistance and the employed mechanisms of antibiotic resistance may differ greatly among microorganisms. It is, therefore, difficult, if not impossible, to directly compare $\mathrm{IC}_{50}$ values for a given AMP when comparing strains. Moreover, the purity of the AMP preparation is of great importance to determine accurately the bactericidal activity of the AMP.

In this study, we optimized the purification of the AMP nisin and determined its $\mathrm{IC}_{50}$ values against the nisinsensitive L. lactis strain NZ9000. Nisin typically purified via a $1 \mathrm{M} \mathrm{NaCl}$ one-step elution yields high levels of active nisin (see above and [28]) but contains a substantial amount of contaminants. We show that these contaminants, which are mainly proteinaceous in nature, are largely removed by using a five-step $\mathrm{NaCl}$ elution. Notably, $400 \mathrm{mM} \mathrm{NaCl}$ (Step II) was sufficient to elute the bulk of the nisin molecules, while the majority of contaminants remain bound to the column. In this manner, a nisin preparation was obtained that exhibited a high specific activity. When tested against the nisin-sensitive L. lactis NZ9000, this highly active nisin exhibited an $\mathrm{IC}_{50}$ of $2.6 \pm 0.1 \mathrm{nM}$, which is a 10 -fold improvement as compared to the nisin obtained via the onestep elution. The potent bactericidal activity of nisin against L. lactis NZ9000 lacking NisI and NisFEG suggests that these 
autoimmunity proteins are of great importance for L. lactis cells that produce nisin (e.g., L. lactis NZ9700).

AMPs get more and more into the focus of biochemical, biophysical, and medical studies due to their antimicrobial activity against a wide variety of bacteria. Here, we report an easy and rapid protocol for the purification of highly active nisin, purified either directly from the culture medium or from a commercially available lyophilized powder. Our studies demonstrate the importance of obtaining AMP preparations with high specific activity. A pure, homogenous, and biologically active preparation will ensure reliable determination of the efficacy of AMPs towards their microbial target(s). Due to the similar chemical and biophysical properties of lantibiotics, our manner of purification may also apply to AMPs other than nisin.

\section{Abbreviations}

$\mathrm{IC}_{50}$ : 50\% Inhibitory concentration

MIC: Minimal inhibitory concentration

MW: Molecular weight

AMP: Antimicrobial peptide.

\section{Author Contributions}

A. Abts and A. Mavaro, contributed equally to this work

\section{Acknowledgments}

The authors thank members of the group for valuable discussions. This work was supported by DFG grant no. Schm1279/10-1 to L. Schmitt and grants from the Heinrich Heine University.

\section{References}

[1] T. R. Klaenhammer, "Genetics of bacteriocins produced by lactic acid bacteria," FEMS Microbiology Reviews, vol. 12, no. 1-3, pp. 39-85, 1993.

[2] C. Chatterjee, M. Paul, L. Xie, and W. A. van der Donk, "Biosynthesis and mode of action of lantibiotics," Chemical Reviews, vol. 105, no. 2, pp. 633-683, 2005.

[3] J. Lubelski, R. Rink, R. Khusainov, G. N. Moll, and O. P. Kuipers, "Biosynthesis, immunity, regulation, mode of action and engineering of the model lantibiotic nisin," Cellular and Molecular Life Sciences, vol. 65, no. 3, pp. 455-476, 2008.

[4] M. Enserink, "Promising antibiotic candidate identified," Science, vol. 286, no. 5448, pp. 2245-2247, 1999.

[5] O. P. Kuipers, M. M. Beerthuyzen, R. J. Siezen, and W. M. De Vos, "Characterization of the nisin gene cluster nisABTCIPR of Lactococcus lactis. Requirement of expression of the nisA and nisI genes for the development of immunity," European Journal of Biochemistry, vol. 216, no. 1, pp. 281-291, 1993.

[6] H. E. Hasper, B. De Kruijff, and E. Breukink, "Assembly and stability of nisin-Lipid II pores," Biochemistry, vol. 43, no. 36, pp. 11567-11575, 2004.

[7] H. E. van Heusden, B. De Kruijff, and E. Breukink, "Lipid II induces a transmembrane orientation of the pore-forming peptide lantibiotic nisin," Biochemistry, vol. 41, no. 40, pp. 12171-12178, 2002.
[8] I. Wiedemann, E. Breukink, C. Van Kraaij et al., "Specific binding of nisin to the peptidoglycan precursor lipid II combines pore formation and inhibition of cell wall biosynthesis for potent antibiotic activity," Journal of Biological Chemistry, vol. 276, no. 3, pp. 1772-1779, 2001.

[9] T. J. Oman and W. A. Van Der Donk, "Insights into the mode of action of the two-peptide lantibiotic haloduracin," ACS Chemical Biology, vol. 4, no. 10, pp. 865-874, 2009.

[10] L. D. Kluskens, A. Kuipers, R. Rink et al., "Post-translational modification of therapeutic peptides by NisB, the dehydratase of the lantibiotic nisin," Biochemistry, vol. 44, no. 38, pp. 12827-12834, 2005.

[11] R. Rink, J. Wierenga, A. Kuipers et al., "Dissection and modulation of the four distinct activities of nisin by mutagenesis of rings A and B and by C-terminal truncation," Applied and Environmental Microbiology, vol. 73, no. 18, pp. 5809-5816, 2007.

[12] C. I. Cheigh, M. C. Kook, S. B. Kim, Y. H. Hong, and Y. R. Pyun, "Simple one-step purification of nisin Z from unclarified culture broth of Lactococcus lactis subsp. lactis A164 using expanded bed ion exchange chromatography," Biotechnology Letters, vol. 26, no. 17, pp. 1341-1345, 2004.

[13] H. J. Choi, C. I. Cheigh, S. B. Kim, and Y. R. Pyun, "Production of a nisin-like bacteriocin by Lactococcus lactis subsp. lactis A164 isolated from Kimchi," Journal of Applied Microbiology, vol. 88, no. 4, pp. 563-571, 2000.

[14] J. Lubelski, R. Khusainov, and O. P. Kuipers, "Directionality and coordination of dehydration and ring formation during biosynthesis of the lantibiotic nisin," Journal of Biological Chemistry, vol. 284, no. 38, pp. 25962-25972, 2009.

[15] R. Rink, J. Wierenga, A. Kuipers et al., "Production of dehydroamino acid-containing peptides by Lactococcus lactis," Applied and Environmental Microbiology, vol. 73, no. 6, pp. 1792-1796, 2007.

[16] M. Uteng, H. H. Hauge, I. Brondz, J. Nissen-Meyer, and G. Fimland, "Rapid two-step procedure for large-scale purification of pediocin-like bacteriocins and other cationic antimicrobial peptides from complex culture medium," Applied and Environmental Microbiology, vol. 68, no. 2, pp. 952-956, 2002.

[17] W. M. de Vos, J. W. Mulders, R. J. Siezen, J. Hugenholtz, and O. P. Kuipers, "Properties of nisin $\mathrm{Z}$ and distribution of its gene, nisZ, in Lactococcus lactis," Applied and Environmental Microbiology, vol. 59, no. 1, pp. 213-218, 1993.

[18] E. M. Bavin, A. S. Beach, R. Falconer, and R. Friedmann, "Nisin in experimental tuberculosis," The Lancet, vol. 259, no. 6699, pp. 127-129, 1952.

[19] W. Brumfitt, M. R. J. Salton, and J. M. T. Hamilton-Miller, "Nisin, alone and combined with peptidoglycan-modulating antibiotics: activity against methicillin-resistant Staphylococcus aureus and vancomycin-resistant enterococci," Journal of Antimicrobial Chemotherapy, vol. 50, no. 5, pp. 731-734, 2002.

[20] E. Severina, A. Severin, and A. Tomasz, "Antibacterial efficacy of nisin against multidrug-resistant Gram-positive pathogens," Journal of Antimicrobial Chemotherapy, vol. 41, pp. 341-347, 1998.

[21] H. Schagger, "Tricine-SDS-PAGE," Nature Protocols, vol. 1, pp. 16-22, 2006.

[22] O. P. Kuipers, P. G. de Ruyter, M. Kleerebezem, and W. M. De Vos, "Quorum sensing-controlled gene expression in lactic acid bacteria," Journal of Biotechnology, vol. 64, no. 1, pp. 1521, 1998.

[23] H. B. van den Berg van Saparoea, P. J. Bakkes, G. N. Moll, and A. J. M. Driessen, "Distinct contributions of the nisin biosynthesis enzymes NisB and NisC and transporter NisT 
to prenisin production by Lactococcus lactis," Applied and Environmental Microbiology, vol. 74, no. 17, pp. 5541-5548, 2008.

[24] P. G. de Ruyter, O. P. Kuipers, and W. M. de Vos, "Controlled gene expression systems for Lactococcus lactis with the foodgrade inducer nisin," Applied and Environmental Microbiology, vol. 62, no. 10, pp. 3662-3667, 1996.

[25] I. Mierau and M. Kleerebezem, "10 Years of the nisincontrolled gene expression system (NICE) in Lactococcus lactis," Applied Microbiology and Biotechnology, vol. 68, no. 6, pp. 705-717, 2005.

[26] L. D. Kluskens, S. A. Nelemans, R. Rink et al., "Angiotensin-(17) with thioether bridge: an angiotensin- converting enzymeresistant, potent angiotensin-(1-7) analog," Journal of Pharmacology and Experimental Therapeutics, vol. 328, no. 3, pp. 849-855, 2009.

[27] Z. Sun, J. Zhong, X. Liang, J. Liu, X. Chen, and L. Huan, "Novel mechanism for nisin resistance via proteolytic degradation of nisin by the nisin resistance protein NSR," Antimicrobial Agents and Chemotherapy, vol. 53, no. 5, pp. 1964-1973, 2009.

[28] N. S. Choi, S. Y. Jeong, H. J. Yang et al., "Activity assay for nisinlike acidic bacteriocins using an optimal $\mathrm{pH}$-conditioned gel matrix," Analytical Biochemistry, vol. 397, no. 2, pp. 259-261, 2010. 

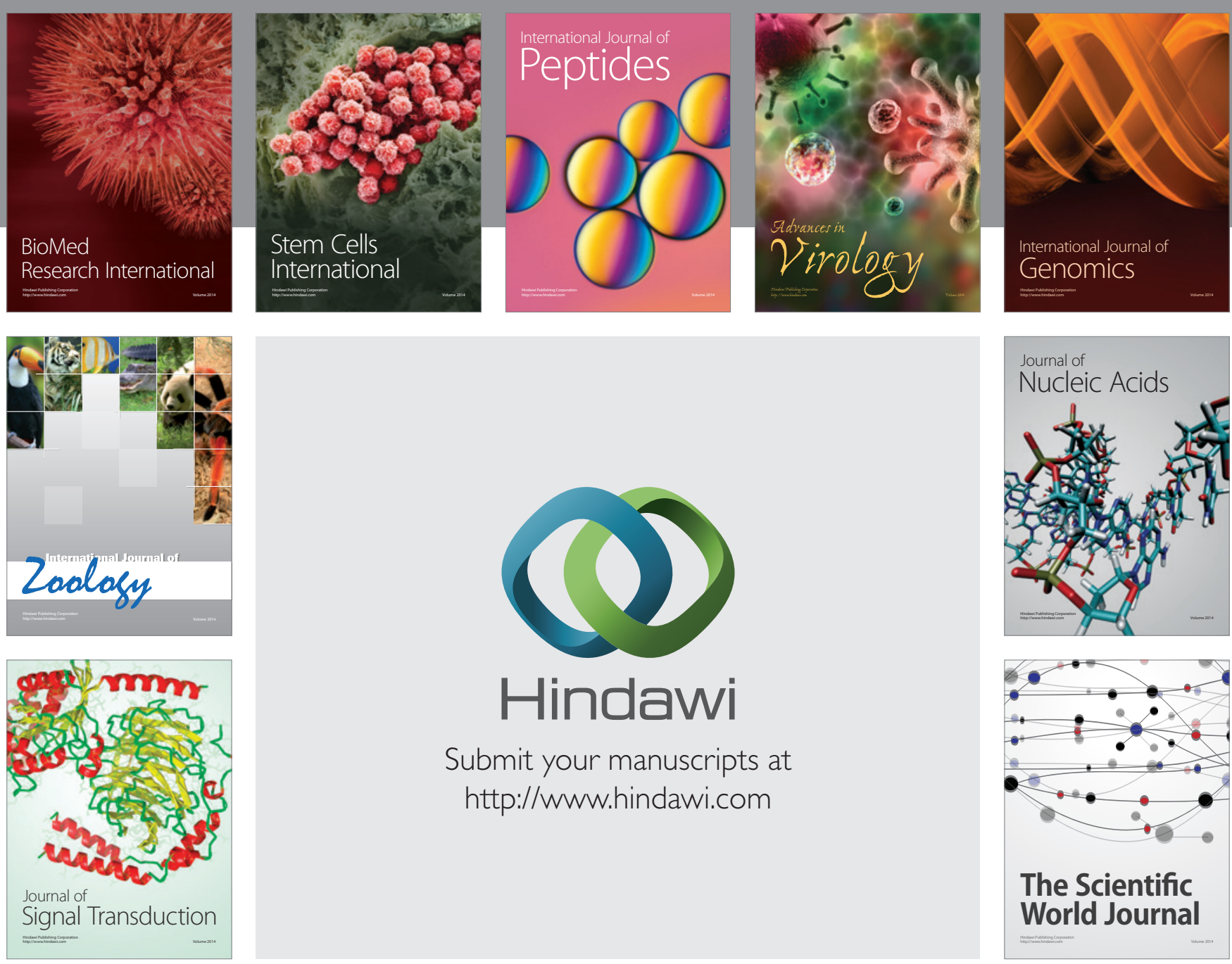

Submit your manuscripts at

http://www.hindawi.com
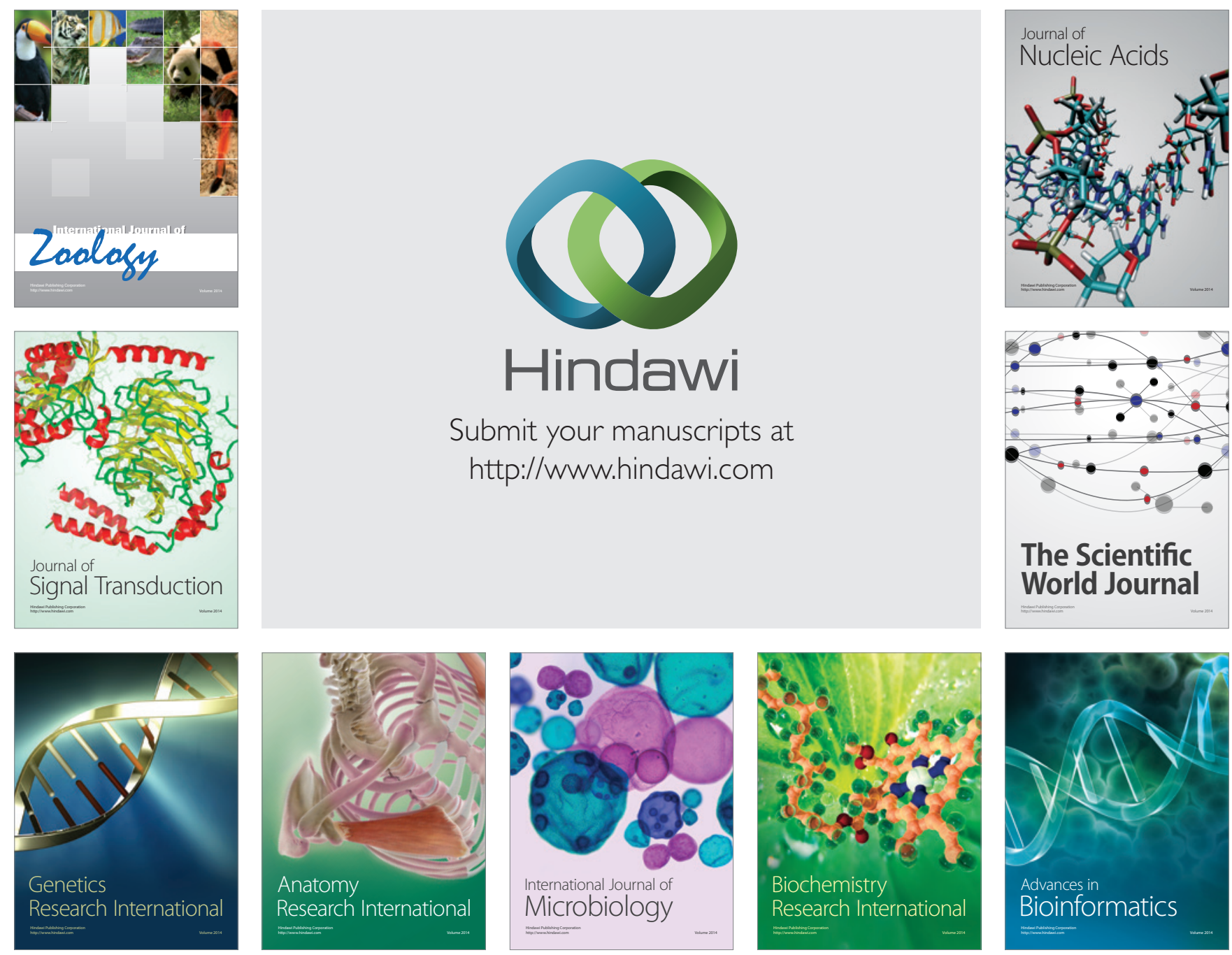

The Scientific World Journal
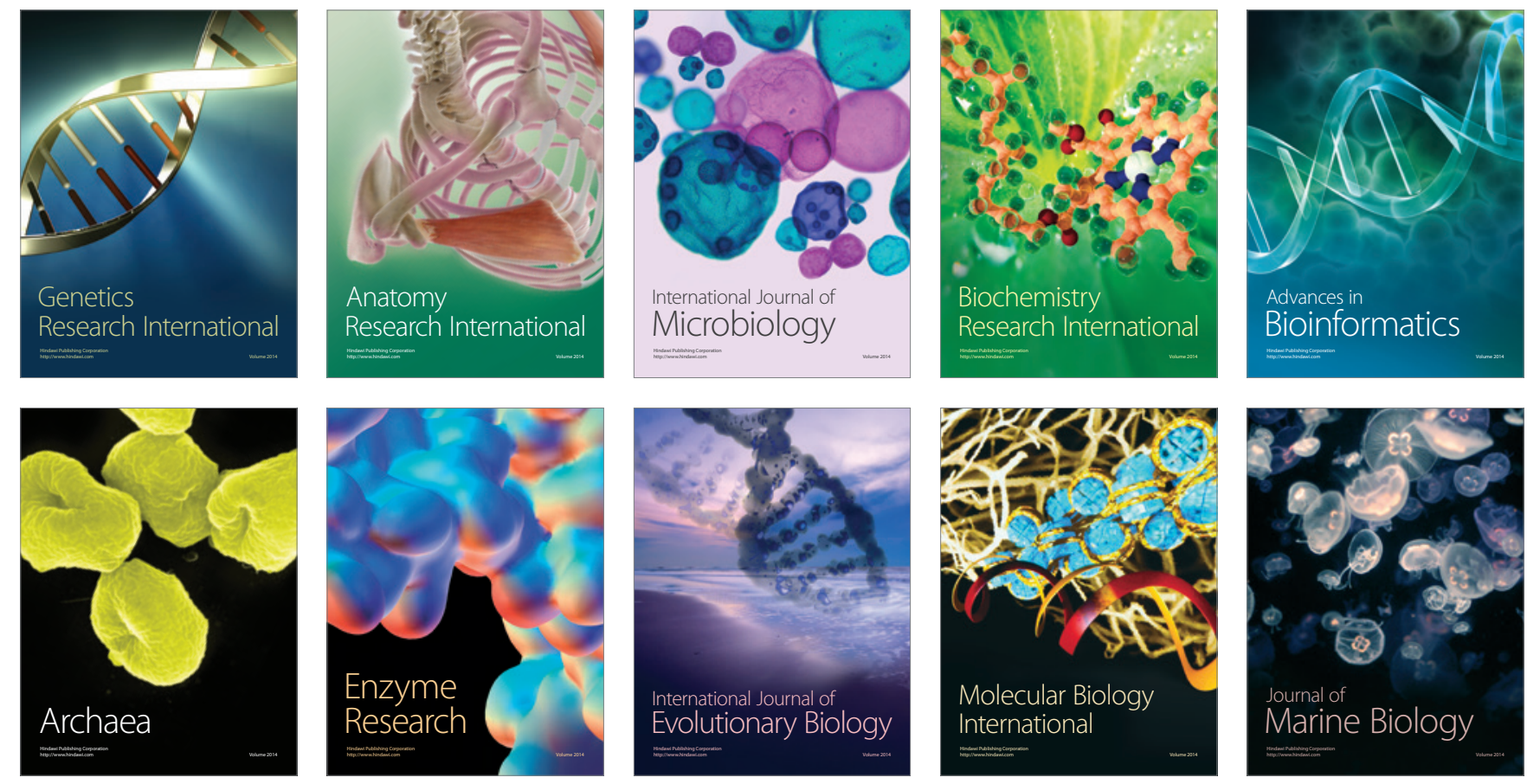